\title{
Financial Analysis of the Access to Pharmacotherapy for Rare Diseases in Bulgaria
}

\author{
Albena Zlatareva1, Konstantin Tachkov1, Milena Stoicheva², Svetla Georgieva ${ }^{3}$, \\ Georgi Momekov', Guenka Petrova ${ }^{2}$ \\ ${ }^{1}$ Faculty of Pharmacy, Medical University of Sofia, Sofia, Bulgaria \\ ${ }^{2}$ Faculty of Public Health, Medical University of Sofia, Sofia, Bulgaria \\ “"Alexandrovska" Hospital, Medical University of Sofia, Sofia, Bulgaria \\ Email: gpetrova@pharmfac.net
}

Received 10 March 2014; revised 10 April 2014; accepted 20 April 2014

Copyright (C) 2014 by authors and Scientific Research Publishing Inc.

This work is licensed under the Creative Commons Attribution International License (CC BY). http://creativecommons.org/licenses/by/4.0/

c) (7) Open Access

\begin{abstract}
The absence of adequate national strategies for rare diseases (RD), high medicines prices and insufficient experts' knowledge creates to the barriers in therapy, as well as the added factors of inappropriate diagnostics and difficulties in peoples' access to health care. A heavier burden is placed on patients' physical, mental, psychological and intellectual wellbeing as well as on the financial capabilities of the third party payers. This study aims to analyze the financial flow for RD therapy as part of the health insurance budget and regional differences in their financing. The point of view is that of the third party payer for a 4-year period. The study is a macro costing top down financial analysis of the expenditures for medicines for rare diseases spent by the 3rd party payer, in Bulgaria that is the national health insurance fund (NHIF). Applied were financial and statistical analyses towards the budget data for expenditures for pharmaceuticals at national and regional level. Results show a constant rise in healthcare medicines expenditures, including those for rare diseases therapy from 20 to 27 million $€$ for a three-year period but it is not above $10 \%$ from the budget for medicines due to regulatory restrictions. A variety of deviations exist among regional counties, accounting for more than $50 \%$ differences in payment per diagnosis. This could be explained with insufficient knowledge and lack of therapeutic standards. There is a need for collaboration on a European level and the creation of a global fund to be able to satisfy therapeutic needs. A closer look at national differences and regional therapy is necessary, as well as standardization of health care services for better health care expenditures management.
\end{abstract}

\section{Keywords}

Healthcare Budget, Medicines Budget, Rare Diseases, Orphan Medicines 


\section{Introduction}

Rare diseases (RD) have a potentially lethal exit, or are chronic highly debilitating diseases with limited spread and high degree of complexity [1]-[4]. Approximately between 5000 and 8000 different rare diseases affect near $6 \%$ of the European population according to the current state of the art scientific knowledge [4]. In Europe it is estimated that 15 million of the inhabitants are suffering or will suffer from RD. As chronic, progressive and degenerative states, they leave patients handicapped for their entire life. Without therapy patients are destined to remain severely injured. In 2008 the European patients' platform (EURORDIS) started an initiative to increase awareness in the society to the problem of RD, their late diagnosis and insufficient therapy information [4]. In June 2000 the same organization established significant discrepancies in the financial and physical access to medicines. The latter was supported by other scientific works, especially in Central and East European Countries showing that the access to orphan medicines for rare diseases therapy is hampered [5]-[7].

The absence of adequate national strategies for $\mathrm{RD}$, high medicines prices and insufficient experts creates to the barriers in therapy, inappropriate diagnostics and difficulties in peoples' access to health care [8] [9]. A heavier burden is placed on patients' physical, mental, psychological and intellectual wellbeing as well as to the financial capabilities of the third party payers.

This study aims to analyze the financial flow for RD therapy as part of the health insurance budget and regional differences in their financing. The point of view is that of the third party payer for 4-year period.

\section{Materials and Methods}

\subsection{Financial Analysis}

The study is a macro costing top down financial analysis of the expenditures for medicines for rare diseases spent by the 3rd party payer. In Bulgaria that is the national health insurance fund (NHIF). The analysis covers the period 2010-2013 year.

The information analyzed was collected from the national yearly financial reports of the healthcare budget. The expenditures for rare diseases and pharmaceuticals paid by the NHIF were systematized per diagnosis, per patient and per region. The international classification of diseases (ICD) 10 was used.

Regional cost differences and index changes were calculated. The cost structure was analyzed by diseases, average on patient and by country regions.

\subsection{Statistical Analysis}

Descriptive statistic and t-test was performed towards the data for the average cost per disease, per patient, and for regional cost differences were. ANOVA analysis was performed to test the statistically significant differences and influencing factors.

\section{Results}

\subsection{Results of the Financial Analysis}

Since 2011 the pharmacotherapy cost of rare diseases is paid by the Ministry of health through a national program for RD with the exception of the therapy for 3 diseases—acromegaly, pulmonary hypertension, and phosphorus metabolism disturbances.

During 2012 the expenditures for pharmacotherapy of rare diseases were reported separately within the health care budget. The financial limit of $10 \%$ was imposed on their increase and thus the access to medicines was limited not only clinically, but also financially. Due to these limitations, a decrease in expenditures for medicines was observed as an absolute value in 2012 in comparison to 2011 [10] (Table 1).

In 2013 the expenditures for pharmaceuticals for RD were included into the total health care budget and were not reported separately. The expenditures for oncology medicines were added, due to the fact that their financial responsibility was transferred to the NHIF from the Ministry of health.

It is evident that there is a substantial growth in the health care expenditures for pharmaceuticals, including the RD therapy and all the changes in expenditures are statistically significant $(\mathrm{p}<0.05)$. The increase in the expenditures is a consequence of not only the changes in budget policy, but also of the changes in the number of the reimbursed diagnoses and medicines which are constantly increasing (Figure 1). 
Table 1. The structure of the NHIF medicines expenditures during 2010-2013 (€).

\begin{tabular}{ccccc}
\hline & $\mathbf{2 0 1 0}$ & $\mathbf{2 0 1 1}$ & $\mathbf{2 0 1 2}$ & $\mathbf{2 0 1 3}$ \\
\hline $\begin{array}{c}\text { Expenditures for medicines, medical } \\
\text { devices, and special foods. }\end{array}$ & $196,546,039$ & $241,654,726$ & $265,377,431$ & $273,855,466$ \\
$\quad \begin{array}{c}\text { Expenditures for medicines } \\
\text { Expenditures for orphan medicines } \\
\text { for rare disease therapy }\end{array}$ & $186,734,423$ & $231,397,613$ & $254,752,527$ & $262,843,378$ \\
\hline
\end{tabular}

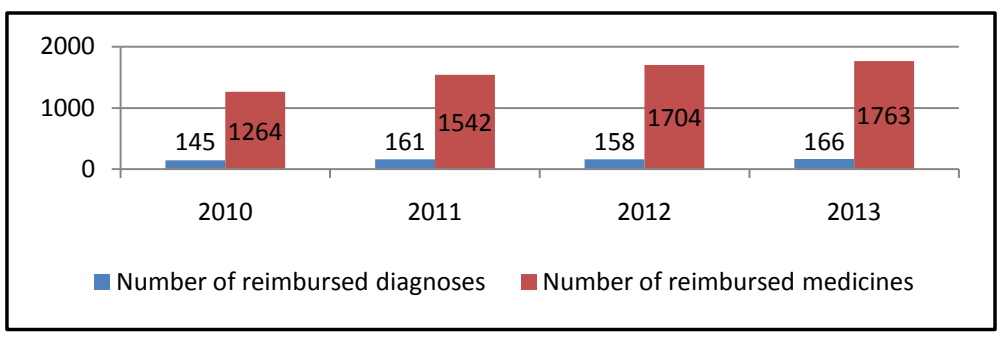

Figure 1. Number of reimbursed diagnoses and medicines in 2010-2013.

The transfer of the cost of pharmacotherapy of rare diseases from the Ministry of Health to the NHIF budget in 2011 gave rise to lots of concerns for budget failure due to the fact that there were no planned expenditures in the previously used financial programs. At the same time, it was observed, an increase in the number of covered diagnoses and eligible patients (Figure 2).

The inherited deficiencies in blood clotting factors, thalassemia, pulmonary hypertension, diseases of Gaucher, Fabry, and cystic fibrosis consume the highest part of health care budget spending and affects the biggest part of all patients suffering from RDs Table 2.

According to the anatomy therapeutic classification (ATC) in 2013 the most often reimbursed medicines fell into almost all codes as ATC A (alimentary tract) $-\mathrm{n}=1$, ATC B (blood and blood formulating organs) - $\mathrm{n}=2$, ATC C (cardiovascular) - $\mathrm{n}=1$, ATC G (genito urinary) - $\mathrm{n}=1$, ATC $\mathrm{J}$ (anti-infective) $-\mathrm{n}=2$, ATC L (oncology) $-\mathrm{n}=4$, varia $\mathrm{V}-\mathrm{n}=1$ (Table 3 ).

Out of the medicines with orphan drug designation for the therapy of rare diseases are reimbursed medicines with expired orphan drug designation or withdrawn such as shown on Table 4 and Table 5.

\subsection{Regional Differences}

Regional differences are extremely high. The highest number of patients with thalassemia is in the capital Sofia (region 22; patients $n=29$ ), followed by Plovdiv (region 16, patients $n=25$ ) the second largest city in the country, but the highest expenditures are paid in Rousse $(n=6)$, and Varna $(n=3)$, where the number of patients is not significant-Figure 3. On average the cost per patient paid by the NHIF at regional level is $17,910 €$, but differences are between $+/-14,000$ Euro among all 28 regions and those differences are statistically significant.

For hemophilia patients the average cost per patients is $41,108 €$ and the regional differences vary among $-16,000$ and $+38,000 €$. The highest is the value in region 05 where only 2 patients with hemophilia are treated. Again the morbidity prevails in the two major cities-Sofia (region 22; patients $n=34$ ) and Plovdiv (region 16; patients $n=24$ ) Gaucher, Fabry and Neyman diseases are classified in one financial group and are the most resource consuming with only 21 patients. The average cost per patient per year of 163,438.29 € and variations are among +120584 and $-87700 €$ (Figures 3-5).

Similar are the results for the other rare diseases expenditures with great variations among the regions and with higher deviations in small regions.

Statistically significant are the differences among the number of patients per disease, reimbursed expenditures per region, and per patient-Table 6.

\section{Discussion}

The budget and regional differences analyses confirm that the therapy of rare diseases consumes a lot of finan- 


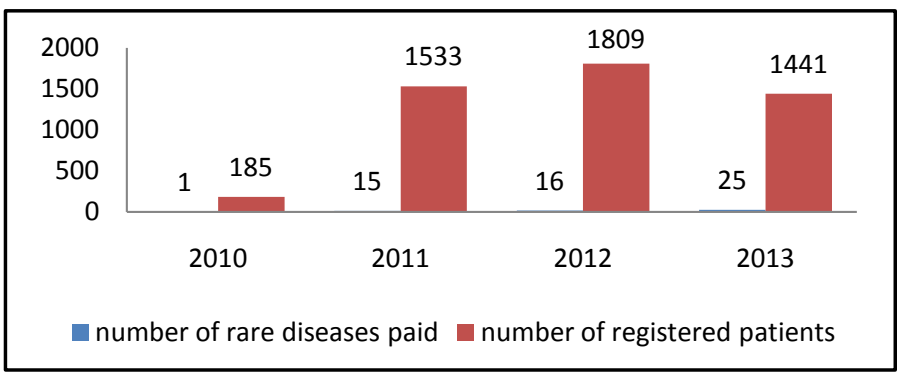

Figure 2. Number of rare disease diagnoses and patients subsidized by NHIF.

Table 2. Number of patients with RD and subsidized sum (€) for their therapy.

\begin{tabular}{|c|c|c|c|c|c|c|c|c|c|}
\hline \multirow[b]{2}{*}{ ICD code } & \multirow[b]{2}{*}{ Diagnosis } & \multicolumn{2}{|c|}{2010} & \multicolumn{2}{|c|}{2011} & \multicolumn{2}{|c|}{2012} & \multicolumn{2}{|c|}{ Jan-July 2013} \\
\hline & & $\mathrm{N}$ of pts & Total sum & $\mathrm{N}$ of pts & Total sum & $\mathrm{N}$ of pts & Total sum & $\mathrm{N}$ of pts & Total sum \\
\hline D56.1 & Thalassemia & & & 219 & $2,621,348$ & 223 & $3,914,598$ & 220 & $2,062,498$ \\
\hline D66 & Inherited deficiencyof factor VIII & & & 226 & $4,611,618$ & 243 & $6,862,510$ & 237 & 4,382,893 \\
\hline D67 & Inherited deficiency of factor IX & & & 22 & 216,214 & 21 & 214,230 & 21 & 124,503 \\
\hline D68.0 & von Willebrand disease & & & 19 & 232,287 & 19 & 228,070 & 19 & 209,577 \\
\hline D68.2 & $\begin{array}{l}\text { Inherited deficit of other } \\
\text { blood clotting factors }\end{array}$ & & & 24 & 919,167 & 15 & 249,156 & 15 & 152,522 \\
\hline D80 - D84 & Immune system disturbances & & & & 0 & & 0 & 2 & 2996 \\
\hline E22.0 & Acromegaly and hypofisis gigantism & 185 & 24,955 & 263 & 597,074 & 241 & $1,163,308$ & 243 & 684,547 \\
\hline E23.0 & Hypopituitarism & & & 76 & 228,110 & 91 & 335,561 & 93 & 158,912 \\
\hline E75.2 & $\begin{array}{c}\text { Gaucher, Fabry and Neyman } \\
\text { Pick disease }\end{array}$ & & & 18 & $2,211,789$ & 21 & $3,529,122$ & 21 & $2,011,257$ \\
\hline E76 & Mucpolissaharoidosis & & & & 0 & 4 & 426,921 & 4 & 816,173 \\
\hline E83.0 & Willsom Konovalov & & & 110 & 15,679 & 144 & 39,019 & 150 & 20,094 \\
\hline E83.3 & $\begin{array}{c}\text { Phosphorous metabolism } \\
\text { disturbance }\end{array}$ & 22 & 2725 & 27 & 2630 & 29 & 2314 & 29 & 1466 \\
\hline E84 & Cystic fibrosis & & & 179 & $1,873,550$ & 184 & $2,331,649$ & 192 & $1,121,815$ \\
\hline I27.0 & Lung hypertension & 120 & 1027 & 126 & 371,316 & 126 & 829,922 & 131 & 551,699 \\
\hline P27.1 & Perinatal bronchial dysplasia & & & 162 & 369,712 & 386 & $1,459,223$ & 0 & $1,201,558$ \\
\hline Q87.1 & Prader Willi syndrome & & & 11 & 22,724 & 13 & 41,876 & 13 & 28,410 \\
\hline Q96 & Turner syndrome & & & 51 & 328,384 & 49 & 381,180 & 48 & 163,855 \\
\hline E74.0 & Pompei disease & & & & 0 & & 0 & 2 & 146,462 \\
\hline \multirow[t]{2}{*}{ E85.1 } & Amiloidosis & & & & 0 & & 0 & 25 & 373,671 \\
\hline & Total & & 2933 & & $14,621,600$ & & $22,008,659$ & & $14,214,908$ \\
\hline
\end{tabular}

cial resources and requires detailed observations and analyses of the medical, humanistic and social reasons for the differences [11]-[13]. Regional differences could be explained with the lack of well-trained personal and specific knowledge for some rare diagnoses [10]. Evidently the lack of medical resources leads to high financial discrepancies which pose a heavy burden on the third party payer. The insufficiency of the well trained staff is also supported by the fact that the discrepancies in financial flows are mainly at regional level. The assumption is that with no knowledge for specific rare diseases the physicians tend to over prescribe unnecessary medica- 
Table 3. Most often reimbursed orphan medicines in 2013.

\begin{tabular}{ccccc}
\hline ATC group & $\begin{array}{c}\text { International } \\
\text { non-proprietary name }\end{array}$ & Dosage form & $\begin{array}{c}\text { Number of packages sold } \\
\text { Jan-August 2013 }\end{array}$ & Reimbursed sum (€) \\
\hline A16AB09 & Idursulfase & Sol for inf. & 87.00 & $1,092,416$ \\
B01AC11 & Iloprost & Nebulaser sol. & 30.00 & 23,076 \\
B02BX04 & Romiplostim & Powder for sol. for inj. & 717.04 & 461,998 \\
C02KX02 & Ambrisentan & Tabl film coated & 34.00 & 84,049 \\
G04BE03 & Sildenafil & Tabl & 190.00 & 99,639 \\
J01GB01 & Tobramycin & Nebulaser sol. & 213.00 & 488,392 \\
J01GB01 & Tobramycin & Inh power, caps & 15.00 & 37,108 \\
L01XE05 & Sorafenib & Film-coatedtabl. & 375.63 & $1,439,816$ \\
L01XE06 & Dasatinib & Film-coatedtabl. & 199.18 & 784,636 \\
L01XE08 & Nilotinib & Caps. hard & 4339.21 & $3,274,735$ \\
L01XE09 & Temsirolimus & Conc. and solv. sol.inf. & 55.20 & 55,196 \\
V03AC03 & Deferazirox & Tabldisp & 6528.00 & $2,516,615$ \\
\hline
\end{tabular}

Table 4. Reimbursed medicines with expired orphan designation in 2013.

\begin{tabular}{ccccc}
\hline ATC group & INN & Dosage form & Number of packages sold January-August 2013 & Reimbursed sum (Euro) \\
\hline A16AB04 & Agalsidase beta & Powder concinf sol & 164.00 & 1150049.44 \\
A16AX06 & Miglustat & Hard caps. & 48.00 & 703694.88 \\
C02KX01 & Bosentan & Tabl film coat. & 208.00 & 1091003.68 \\
H01AX01 & Pegvisomant & Powder sol inj & 34.00 & 142266.64 \\
\hline
\end{tabular}

Table 5. Reimbursed medicines with withdrawn orphan designation in 2013.

\begin{tabular}{ccccc}
\hline ATC group & $\begin{array}{c}\text { International } \\
\text { non-proprietary name }\end{array}$ & Dosage form & $\begin{array}{c}\text { Number of packages sold } \\
\text { January-August 2013 }\end{array}$ & Reimbursed sum (Euro) \\
\hline B02BX05 & Eltrombopac & Tabl. film coat & 454.00 & 3087014.64 \\
L01XE01 & Imatinib & Film-coatedtabl. & 590.95 & 2709839.49 \\
L01XE04 & Sunitinib & Caps. hard & 425.43 & 3734256.55 \\
L01XE11 & Pazopanib & Film-coatedtabl. & 532.76 & 3190953.30 \\
\hline
\end{tabular}

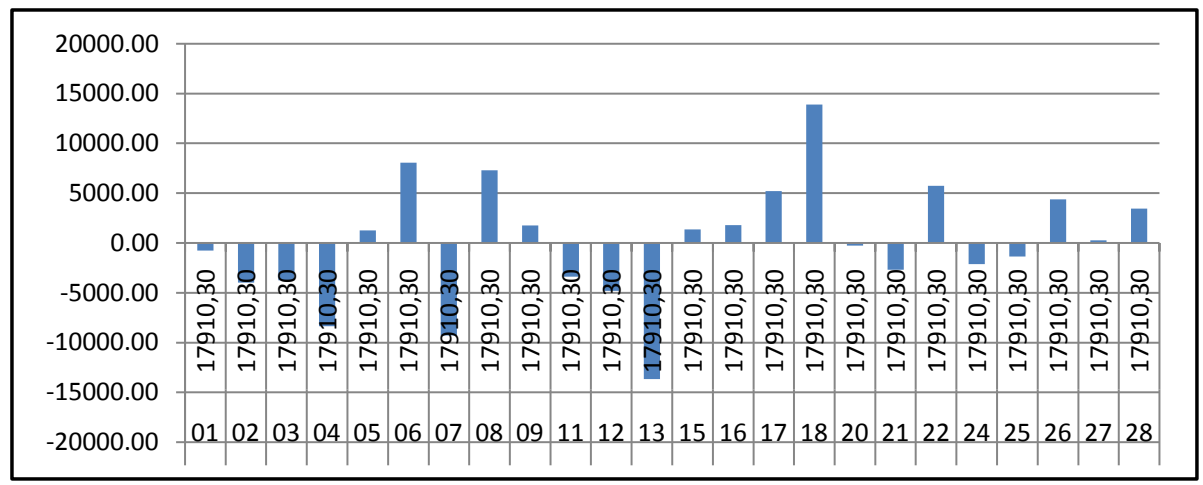

Figure 3. Regional cost differences for patients with thalassemia. 


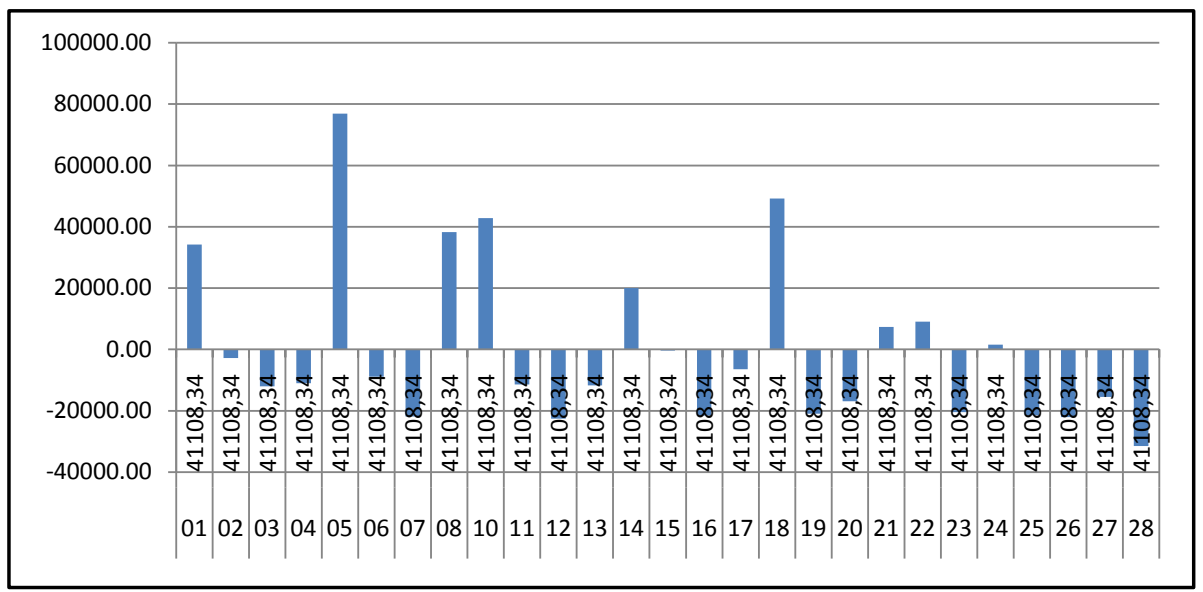

Figure 4. Regional cost differences for patients with hemophilia.

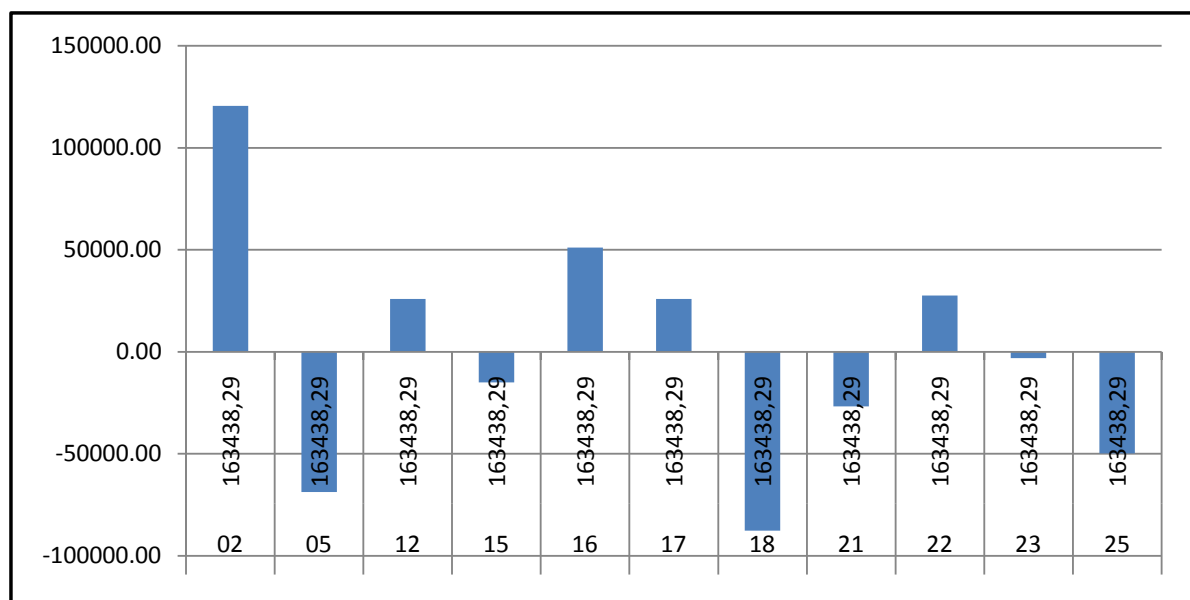

Figure 5. Regional cost differences for patients with Gaucher, Fabry and Neyman diseases.

Table 6. One way ANOVA analysis of statistical differences among the expenditures.

\begin{tabular}{ccccccc}
\hline & & Sum of squares & Df & Mean square & F & Sig. \\
\hline $\begin{array}{c}\text { Average monthly } \\
\text { number of } \\
\text { patients }\end{array}$ & Between groups & $3,071,436$ & 27 & 113,757 & 5246 & 0.000 \\
& Within groups & $6,266,638$ & 289 & 21,684 & & \\
Total & $9,338,074$ & 316 & & & \\
$\begin{array}{c}\text { Reimbursed } \\
\text { Expenditures }\end{array}$ & Between groups & $3.961 \mathrm{E} 12$ & 27 & $1.467 \mathrm{E} 11$ & 1593 & 0.034 \\
& Within groups & $2.661 \mathrm{E} 13$ & 289 & $9.207 \mathrm{E} 10$ & & \\
& Total & $3.057 \mathrm{E} 13$ & 316 & & & \\
$\begin{array}{c}\text { Average cost per } \\
\text { patient }\end{array}$ & Between groups & $1.479 \mathrm{E} 11$ & 27 & $5.477 \mathrm{E} 9$ & 0.545 & 0.970 \\
& Within groups & $2.885 \mathrm{E} 12$ & 287 & $1.005 \mathrm{E} 10$ & & \\
& Total & $3.033 \mathrm{E} 12$ & 314 & & & \\
\hline
\end{tabular}

tions and thus exceed the financial limits [1]. This is in contrast with other studies revealing that in small cities the prescribing of medicines is usually more restrictive and less costly [8]. 
Regional differences in financial resources support the need for revision and reasoning of their medical basis. The patients with rare diseases are extremely limited in number but they consume huge amount of the scarce health insurance budget [5]. Every deviation in their therapy should be precisely revised and timely corrected not only to guarantee the necessary medical results, but also to control budget spending. The high expenditures in this group of patients could not always mean better therapeutic results.

\section{Conclusions}

Within the framework of the very dynamic regulatory environment and extensive scientific work in the field of rare diseases therapy, the financial resources remain extremely limited to ensure appropriate therapy and scientifically based treatment. There is a need of collaboration on a European level and the creation of a global fund to be able to satisfy therapeutic needs.

A closer look at national differences and regional therapy is necessary, as well as standardization of health care services for better health care expenditures management.

\section{References}

[1] EC (2007) Rare Diseases Challenge for the Society. www.ec.europa.eu/health/archive/ph_threats/non_com/docs/raredis_comm_bg.pdf

[2] European Parliament and EC. Decision No. 1295/1999/EU from 29 April 1999 for the Acceptance of Actions of the Community for Rare Diseases Prophylactics within the Context of the Public Health Activities; OB L 155, 22.6.1999, page 1; Changed with Decision No. 1786/2002/EU (OB L 271, 9.10.2002).

[3] Orphanet (2010) Prevalence of Rare Diseases in Bulgaria. http://www.medicine.bg/novini/nad-polovin-milion-balgari-stradat-ot-redki-bolesti

[4] Ministry of Health National Program for Rare Diseases (2012) www.rare-bg.com/wp-content/uploads/2013/01/NPRD_2009-20131.doc

[5] Schey, C., Milanova, T. and Hutchings, A. (2011) Estimating the Budget Impact of Orphan Medicines in Europe: 2010-2020. Orphanet Journal of Rare Diseases, 27, 62. http://dx.doi.org/10.1186/1750-1172-6-62

[6] Kamusheva, M., Stoimenova, A., Doneva, M., Zlatareva, A. and Petrova, G. (2013) A Cross Country Comparison of Reimbursed Orphan Medicines in Bulgaria, Greece, Macedonia. Biotechnology and Biotechnology Equipment, 27, 4186-4193. http://dx.doi.org/10.5504/BBEQ.2013.0066

[7] Zlatareva, A., Lakic, D., Kamusheva, M., Spaskov, D., Georgi, M. and Guenka, P. (2013) Analysis of Access to Orphan Drugs in Five Neighboring European Countries-Bulgaria, Greece, Macedonia, Romania and Serbia. World Journal of Pharmacy and Pharmaceutical Sciences, 2, 4415-4434.

[8] Savova, A., Kamusheva, M., Georgieva, S., Stoimenova, A. and Petrova, G. (2013) Budget Impact Analysis of Chronic Myeloid Leukemia Treatment in Bulgaria. Biotechnology and Biotechnology Equipment, 27, 3595-3598. http://dx.doi.org/10.5504/BBEQ.2012.0075

[9] Inotai, A., Petrova, G., Vitezic, D. and Kaló, Z. (2014) Benefits of Investment into Modern Medicines in CentralEastern European Countries. Experts Review of Pharmacoeconomics and Outcomes Research, 14, 71-79. http://dx.doi.org/10.1586/14737167.2014.868314

[10] INFOPACK (2010) Patient Care, a Public Affair. EURORDIS, European Union. http://download.rarediseaseday.org/Rare\%20Disease\%20Day\%20Info\%20pack\%202009.pdf

[11] MH (2009) National Council for Rare Diseases. National Program for Rare Diseases for the Period. http://www.mh.government.bg/Articles.aspx?lang=bg-BG\&

[12] Bignami, F. (2007) Eurordis Survey on Orphan Drugs Availability in Europe. Presented at the 6th Eurordis Round Table of Companies Workshop, Barcelona. http://www.eurordis.org/IMG/pdf/2007ODsurvey-eurordis.pdf

[13] Simoens, S. (2011) Pricing and Reimbursement of Orphan Drugs: The Need for More Transparency. Orphanet Journal of Rare Diseases, 6, 42. http://dx.doi.org/10.1186/1750-1172-6-42 